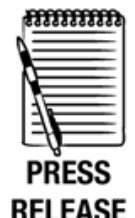

RELEASE

\title{
Patterns of fetal and infant growth are related to atopy and wheezing disorders at age 3 years
}

\author{
Katharine C Pike, ${ }^{1}$ Sarah R Crozier, ${ }^{2}$ Jane S A Lucas, ${ }^{1,3}$ Hazel M Inskip, ${ }^{2}$
} Sian Robinson, ${ }^{2}$ The Southampton Women's Survey Study Group, ${ }^{2}$ Graham Roberts, ${ }^{1,3}$ Keith M Godfrey ${ }^{2,4}$

- Additional materials are published online only. To view these files please visit the journal online (http://thorax.bmj. com)

${ }^{1}$ Child Health, University of Southampton School of

Medicine, Southampton, UK ${ }^{2}$ Medical Research Council Lifecourse Epidemiology Unit, University of Southampton, Southampton, UK

${ }^{3}$ Southampton NIHR Respiratory Biomedical Research Unit, Southampton University Hospitals Trust, Southampton, UK

${ }^{4}$ Southampton NIHR Nutrition, Diet and Lifestyle Biomedical Research Unit, Southampton University Hospitals Trust, Southampton, UK

\section{Correspondence to} Professor Keith M Godfrey, Medical Research Council Lifecourse Epidemiology Unit, Southampton General Hospital Tremona Road, Southampton S016 6YD, UK

kmg@mrc.soton.ac.uk

Received 6 January 2010 Accepted 6 August 2010 Published Online First 18 October 2010

\begin{abstract}
Background Little is known about whether patterns of early growth are associated with altered respiratory and immune development. This study relates prenatal and infant growth patterns to wheeze and atopy at age 3 years.
\end{abstract}

Methods Birth weight and length were measured in 1548 children born at term. Conditional fetal head and abdominal circumference growth velocities were calculated from antenatal ultrasound measurements. Conditional postnatal growth velocities were calculated from infant weight, length and adiposity data. Measures of size and conditional growth were related to parentallyreported infant and early childhood wheeze and to atopic status at age 3 years

Results The risk of atopy increased by $46 \%$ per SD increase in abdominal circumference growth velocity from 11 to 19 weeks gestation but by 20\% per SD decrease in abdominal growth velocity from 19 to 34 weeks ( $p=0.007$ and $p=0.011$, respectively). The risk of atopic wheeze increased by $20 \%$ per SD decrease in 19-34-week abdominal growth $(p=0.046)$. The risk of non-atopic wheeze increased by $10 \%$ per SD decrease in 11-19-week head circumference growth. Greater relative infant weight and adiposity gains were associated with both atopic and non-atopic wheeze.

Conclusions $A$ rapid growth trajectory during 11-19 weeks gestation followed by late gestation growth faltering is associated with atopy, suggesting that influences affecting fetal growth may also alter immune development. A lower early fetal growth trajectory is associated with non-atopic wheeze, possibly reflecting an association with smaller airways. An association between postnatal adiposity gain and wheeze may partly reflect prenatal influences that cause fetal growth to falter but are then followed by postnatal adiposity gain.

\section{INTRODUCTION}

Children and adults who were small at birth tend to have reduced lung function and an increased risk of respiratory mortality and morbidity. ${ }^{1-3}$ Smaller birth size is associated with reduced lung function from early infancy, ${ }^{1-7}$ and genetic and environmental influences on early lung development appear to have lasting effects on later respiratory health. ${ }^{8}$ It has been proposed that an adverse intrauterine environment might induce fetal adaptations which restrict somatic growth and also have adverse functional consequences for the developing immune system and lungs. ${ }^{3}$

Studies examining the association between birth anthropometry and later asthma have, however, had inconsistent findings, ${ }^{2}$ and children who had experienced intrauterine growth retardation had decreased lung function but no difference in wheeze compared with children of appropriate birth weight for gestational age. ${ }^{1}$ The inconsistency may partly reflect methodological differences including adequacy of correction for gestation and other confounding factors. In twin studies, birth weight exerts a greater influence on later asthma in monozygotic twins than in dizygotic twin pairs, suggesting fetal growth and childhood asthma may be associated independently of shared genetic factors. ${ }^{9} 10$

In healthy term infants within the normal birth weight range, we previously found that smaller birth size and rapid postnatal weight gain were associated with reduced lung function at age 5-14 weeks. ${ }^{4}$ Subsequent studies showed an inverse relationship between infant lung function and early postnatal weight gain in premature infants, ${ }^{5}$ and also that change in lung function between 1 and 12 months is inversely related to infant weight gain. ${ }^{11}$ Rapid postnatal weight gain can result from prenatal growth restriction and we hypothesised that faltering growth in late gestation might be associated with later respiratory ill health. ${ }^{4}$

Studies to date have generally used birth anthropometry as a proxy for fetal growth, and no previous study in an unselected population has used detailed characterisation of prenatal and postnatal growth patterns from longitudinal anthropometric data collected before and after birth. Here we measured fetal size longitudinally and derived conditional head and abdominal circumference growth velocities to assess both the early trajectory of fetal growth and faltering of abdominal growth in late gestation; the latter is recognised as an important fetal adaptation to an adverse intrauterine environment which acts to protect brain growth. ${ }^{12} 13$ We also derived conditional velocities of postnatal weight and adiposity gain because prenatal growth faltering may lead to an increased rate of infant weight gain. We then examined the relationships between antenatal and postnatal growth parameters and early childhood wheeze and atopy.

\section{METHODS \\ Study population}

Offspring of participants in the Southampton Women's Survey were studied. ${ }^{14}$ Between 1998 and 2002, 12583 women aged 20-34 years were 
recruited; those who became pregnant were followed through pregnancy and their children visited at 6, 12, 24 and 36 months. We excluded infants born at $<37$ weeks gestation to avoid confounding effects of abnormal lung development associated with prematurity. By December 2003, 1868 term infants were born; 1548 (83\%) were followed up at age 3 years, with 98\% seen at all four postnatal visits.

\section{Growth variables}

Gestational age was determined using an algorithm combining last menstrual period and early ultrasound data. Using Acuson $128 \mathrm{XP}$, Aspen and Sequoia ultrasound machines calibrated to $1540 \mathrm{~m} / \mathrm{s}$, experienced research ultrasonographers used standardised anatomical landmarks to measure fetal head and abdominal circumferences at 11,19 and 34 weeks gestation. Research nurses measured weight and crown-heel length at birth, and weight, length and subscapular skinfold thickness at 6 and 12 months.

\section{Respiratory symptoms}

At 6, 12, 24 and 36 months, mothers were asked whether their child had 'experienced any episodes of chestiness associated with wheezing or whistling in his/her chest since they were last seen'. A positive response on any visit was considered evidence of early childhood wheeze.

\section{Atopic status}

Atopy at age 3 years was defined as skin prick test reactivity to any of the following allergens: cat, dog, house dust mite, milk, grass pollens (all from Hollister-Stier, Spokane, Washington, USA) or egg (Alyostal, Antony, France) $\geq 3 \mathrm{~mm}$ in diameter in the presence of appropriate positive and negative controls. Maternal atopic status was assessed at the 12-month interview.

\section{Statistical analysis}

The method of Royston was used to calculate conditional measures of fetal size and infant length and weight, correcting for exact age at measurement and regression to the mean. ${ }^{15}$ Velocities of prenatal and infant growth were calculated from change in size adjusted for gestation or age, as appropriate. For subscapular skinfold thickness, the method of Royston proved unsuitable as adiposity does not increase monotonically with age; subscapular skinfold growth velocity conditional upon initial size was calculated using regression. Anthropometric and growth velocity variables were logarithmically transformed to achieve normality and then standardised to z-scores. Outcomes were expressed in units of change in outcome per SD change in predictor. All outcome variables were binary but common, therefore Poisson regression with robust variance was used to derive relative risks. Logistic regression was not used as ORs relating to common outcomes are hard to interpret. ${ }^{16}$

Relative risks were determined for two primary outcomes: 'early childhood wheeze' and 'atopy', comparing children with and without each condition. Children who were reported to wheeze were divided according to atopic status to form two secondary outcomes-'atopic wheeze' and 'non-atopic wheeze'; children in these groups were compared with non-atopic children who had never wheezed. Table 1 in the online supplement shows the potential confounders examined. Regression models were built including confounders significantly associated with each outcome in a mutually adjusted model $(p<0.05)$ and key factors thought essential to adjust for because of potential biological significance (maternal education, maternal atopy and child's birth order for atopy at 3 years and atopic wheeze; maternal education, smoking in pregnancy, maternal asthma, paternal asthma and child's birth order for early childhood wheeze and non-atopic wheeze). Adjusted and unadjusted relative risks are presented for birth anthropometry and prenatal and postnatal growth velocities; relative risks for static measures of fetal size are presented in the online supplement. Analyses were performed using Stata 11 (StataCorp).

\section{RESULTS}

Table 1 shows the wide variation in the characteristics of the children seen at 3 years. Cohort members not seen had lower birth weight and their mothers were younger, more likely to smoke, less likely to have tried breastfeeding and had lower educational attainment.

Atopic status was known for 1342 mothers (87\%) and 1184 children (76\%); 199 children (17\%) were atopic. Wheeze status to age 3 years was known for 1522 children (98\%); 890 children (58\%) had ever experienced wheeze. Both wheeze and atopy data were available for 1164 children; of these, 127 (11\%) had wheezed and were atopic, 555 (48\%) had wheezed but were not

Table 1 Characteristics of children who were and were not seen at age 3 years

\begin{tabular}{|c|c|c|c|}
\hline Parental characteristics & $\begin{array}{l}\text { Children seen at } \\
3 \text { years }(n=1548)\end{array}$ & $\begin{array}{l}\text { Children not seen at } \\
3 \text { years }(n=320)\end{array}$ & $\begin{array}{l}\mathrm{p} \\
\text { Value }\end{array}$ \\
\hline $\begin{array}{l}\text { Mean (SD) mother's age at } \\
\text { child's birth (years) }\end{array}$ & $30.2(3.8)$ & $29.4(3.8)$ & \\
\hline $\begin{array}{l}\text { Mother's education A level or } \\
\text { above, } \mathrm{n}(\%)\end{array}$ & $900(57 \%)$ & $150(47 \%)$ & \\
\hline $\begin{array}{l}\text { Maternal smoking during } \\
\text { pregnancy, } \mathrm{n}(\%)\end{array}$ & $245(16 \%)$ & $80(27 \%)$ & \\
\hline Maternal asthma, n (\%) & $344(22 \%)$ & $74(24 \%)$ & \\
\hline $\begin{array}{l}\text { Maternal eczema in } \\
\text { childhood, } \mathrm{n}(\%)\end{array}$ & $275(18 \%)$ & $50(16 \%)$ & \\
\hline Maternal rhinitis, n (\%) & $639(42 \%)$ & $118(38 \%)$ & \\
\hline Paternal asthma, n (\%) & $264(17 \%)$ & $60(20 \%)$ & \\
\hline $\begin{array}{l}\text { Paternal eczema in } \\
\text { childhood, } \mathrm{n}(\%)\end{array}$ & $156(11 \%)$ & $31(10 \%)$ & \\
\hline Paternal rhinitis, n (\%) & $506(34 \%)$ & $102(34 \%)$ & \\
\hline
\end{tabular}

\section{Birth characteristics}

Mean (SD) birth weight

Mean (SD) gestational age (weeks)

Primiparous, $n(\%)$

Attempted breastfeeding

$\mathrm{n}(\%)^{*}$

$\begin{array}{rcr}3525(475) & 3456(467) & 0.020 \\ 40.1(1.2) & 40.1(1.2) & 0.909 \\ & & \\ 704(46 \%) & 114(36 \%) & 0.001 \\ 1269(83 \%) & 162(70 \%) & <0.001\end{array}$

Characteristics at 6-month follow-up*

Maternal smoking, $\mathrm{n}(\%) \quad 284(18 \%)$

Other smokers in the home, $\quad 461(31 \%)$

$\begin{array}{rr}73(30 \%) & <0.001 \\ 86(35 \%) & 0.145 \\ 83(34 \%) & 0.013 \\ 105(43 \%) & 0.384\end{array}$

$\begin{array}{llrl}\text { Ever wheezed, } \mathrm{n}(\%) & 402(26 \%) & 83(34 \%) & 0.013 \\ \end{array}$

Characteristics at 1-year follow-up*

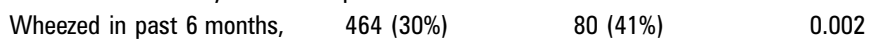

$\mathrm{n}(\%)$

Cat or dog in home, $n(\%) \quad 675(44 \%) \quad 82(42 \%) \quad 0.575$

Characteristics at 2-year follow-up*

Wheezed in past year, $\mathrm{n}(\%) \quad 414(27 \%)$

$28(27 \%)$

0.954

${ }^{*}$ Of the 320 children not seen at 3 years, 247 were seen at 6 months, 196 at 1 year and 104 at 2 years. 


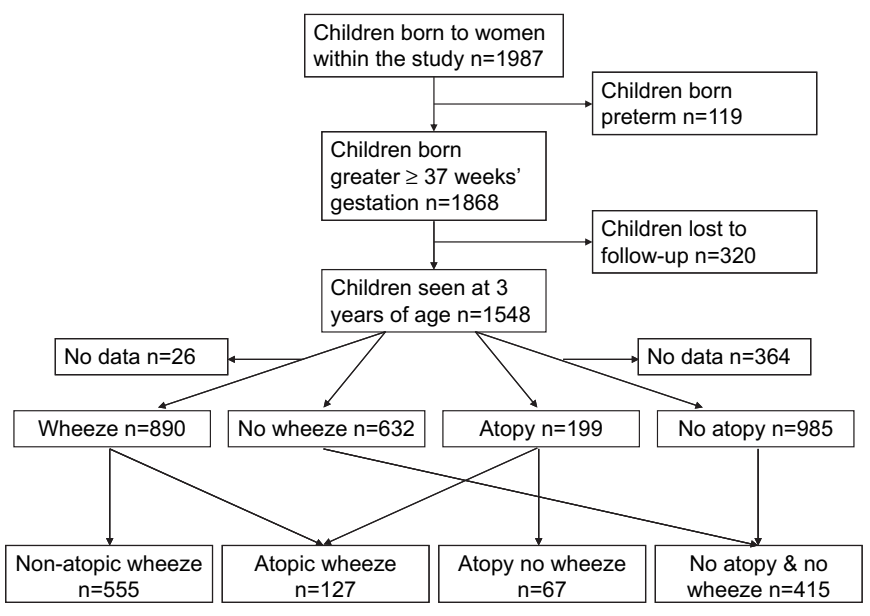

Figure 1 Study outline and numbers included in outcome groups.

atopic, 67 (6\%) had never wheezed but were atopic and 415 $(36 \%)$ had never wheezed and were not atopic (figure 1).

\section{Atopy at age 3 years}

The RR of atopy at 3 years increased by $46 \%$ per SD increase in abdominal circumference growth velocity from 11 to 19 weeks gestation ( $\mathrm{p}=0.007$, table 2$)$ and was higher in children who had a larger abdominal circumference at 19 weeks gestation $(R R=1.24$ per $S D, p=0.02$, see table 2 in online supplement). In contrast, each SD increase in abdominal growth velocity from 19 to 34 weeks gestation decreased the risk of atopy by $20 \%$ $(p=0.01$, table 2$)$. The risk of atopy was associated with greater crown-heel length at birth $(R R=1.17$ per $S D, p=0.03)$ but not with prenatal head circumference growth, birth weight or measures of postnatal growth velocity. The results were similar when sensitisation to food allergens was excluded from the definition of atopy.

\section{Early childhood wheeze}

Early childhood wheeze was not significantly associated with either fetal measurements (see table 3 in online supplement) or birth weight or length (table 3), but was associated with greater weight and adiposity gains both between birth and 6 months ( $5 \%$ per SD increase, $\mathrm{p}=0.02$ for both) and from 6 to 12 months ( $6 \%$ per SD increase in weight, $p=0.04,7 \%$ per SD increase in adiposity gain, $p=0.001)$. There was no association between early childhood wheeze and postnatal gain in length.

\section{Atopic wheeze}

The pattern of risk for atopic wheeze was similar to that for atopy (tables 2 and 4). RR increased with higher 11-19-week abdominal growth velocity ( $32 \%$ per $\mathrm{SD}, \mathrm{p}=0.1$ ), larger 19 -week fetal abdominal circumference ( $34 \%$ increase per $\mathrm{SD}, \mathrm{p}=0.02$, see table 4 in online supplement) and lower 19-34-week abdominal growth velocity $(20 \%$ per $\mathrm{SD}, \mathrm{p}=0.046)$. The risk of atopic wheeze was not associated with prenatal head circumference growth, weight or crown-heel length at birth $(p=0.3$, table 4 in online supplement), but was associated with greater weight and adiposity gains in infancy (table 4). SD increases in subscapular skinfold gain and weight gain between birth and 6 months were associated with increases in the risk of atopic wheeze of $27 \%$ $(p=0.002)$ and $22 \%(p=0.02)$, respectively; each SD increase in subscapular skinfold gain between 6 and 12 months was associated with a $20 \%$ increase in the risk of atopic wheeze $(p=0.02)$. In contrast, postnatal length gain was not associated with the risk of atopic wheeze.

\section{Non-atopic wheeze}

The associations between fetal growth and risk of non-atopic wheeze differed from those for atopic wheeze. Non-atopic wheeze was not associated with higher 11-19-week abdominal growth velocity followed by abdominal growth faltering, but instead increases in risk were seen for lower head circumference

Table 2 Adjusted relative risk (RR) for associations between fetal and infant growth and atopy at age 3 years $(\mathrm{N}=1184)$

\begin{tabular}{|c|c|c|c|c|c|c|c|c|}
\hline & \multicolumn{4}{|c|}{ Unadjusted analyses } & \multicolumn{4}{|c|}{ Adjusted* analyses } \\
\hline & $\overline{\mathbf{R R}}$ & (95\% Cl) & p Value & $\mathbf{n}$ & $\mathbf{R R}$ & $(95 \% \mathrm{Cl})$ & p Value & $\mathbf{n}$ \\
\hline \multicolumn{9}{|l|}{ Birth size variables } \\
\hline Crown-heel length & 1.20 & 1.06 to 1.36 & 0.005 & 1149 & 1.17 & 1.01 to 1.34 & 0.032 & 1004 \\
\hline Weight & 1.10 & 0.97 to 1.25 & 0.137 & 1171 & 1.08 & 0.95 to 1.24 & 0.241 & 1023 \\
\hline \multicolumn{9}{|l|}{ Conditional fetal growth } \\
\hline \multicolumn{9}{|l|}{$11-19$ weeks } \\
\hline Head circumference & 0.93 & 0.72 to 1.18 & 0.534 & 464 & 0.80 & 0.60 to 1.06 & 0.123 & 405 \\
\hline Abdominal circumference & 1.44 & 1.20 to 1.86 & 0.005 & 431 & 1.46 & 1.11 to 1.93 & 0.007 & 378 \\
\hline \multicolumn{9}{|l|}{ 19-34 weeks } \\
\hline Head circumference & 0.96 & 0.81 to 1.13 & 0.608 & 682 & 0.98 & 0.82 to 1.17 & 0.817 & 601 \\
\hline Abdominal circumference & 0.80 & 0.69 to 0.94 & 0.006 & 707 & 0.80 & 0.68 to 0.95 & 0.011 & 625 \\
\hline \multicolumn{9}{|l|}{$\underline{\text { Conditional infant growth }}$} \\
\hline \multicolumn{9}{|l|}{$0-6$ months } \\
\hline Length & 0.93 & 0.83 to 1.05 & 0.244 & 1131 & 0.89 & 0.78 to 1.02 & 0.104 & 991 \\
\hline Weight & 1.09 & 0.97 to 1.22 & 0.131 & 1157 & 1.06 & 0.92 to 1.21 & 0.416 & 1013 \\
\hline Subscapular skinfold & 1.09 & 0.97 to 1.23 & 0.157 & 1153 & 1.09 & 0.96 to 1.24 & 0.185 & 1011 \\
\hline \multicolumn{9}{|l|}{$6-12$ months } \\
\hline Length & 1.08 & 0.93 to 1.26 & 0.326 & 1069 & 1.02 & 0.86 to 1.21 & 0.843 & 941 \\
\hline Weight & 1.00 & 0.83 to 1.19 & 0.961 & 1086 & 1.03 & 0.84 to 1.26 & 0.778 & 956 \\
\hline Subscapular skinfold & 1.05 & 0.92 to 1.20 & 0.485 & 1078 & 1.11 & 0.97 to 1.27 & 0.142 & 950 \\
\hline
\end{tabular}


Table 3 Relative risks (RR) for the associations between prenatal and postnatal growth and whether the child had ever wheezed by age 3 years (unadjusted and adjusted) ( $\mathrm{N}=1522)$

\begin{tabular}{|c|c|c|c|c|c|c|c|c|}
\hline & \multicolumn{4}{|c|}{ Unadjusted analyses } & \multicolumn{4}{|c|}{ Adjusted* analyses } \\
\hline & $\overline{\mathbf{R R}}$ & $(95 \% \mathrm{Cl})$ & p Value & $\mathbf{n}$ & $\mathbf{R R}$ & $(95 \% \mathrm{CI})$ & p Value & $\mathbf{n}$ \\
\hline \multicolumn{9}{|l|}{ Birth size variables } \\
\hline Crown-heel length & 0.96 & 0.92 to 1.00 & 0.061 & 1479 & 0.96 & 0.92 to 1.01 & 0.088 & 1479 \\
\hline Weight & 0.97 & 0.93 to 1.01 & 0.197 & 1506 & 0.97 & 0.93 to 1.02 & 0.206 & 1506 \\
\hline \multicolumn{9}{|l|}{ Conditional fetal growth } \\
\hline \multicolumn{9}{|l|}{$11-19$ weeks } \\
\hline Head circumference & 0.98 & 0.91 to 1.06 & 0.574 & 597 & 0.94 & 0.87 to 1.02 & 0.155 & 597 \\
\hline Abdominal circumference & 0.98 & 0.89 to 1.07 & 0.611 & 562 & 0.95 & 0.87 to 1.04 & 0.285 & 562 \\
\hline \multicolumn{9}{|l|}{ 19-34 weeks } \\
\hline Head circumference & 0.98 & 0.93 to 1.04 & 0.598 & 877 & 0.98 & 0.93 to 1.04 & 0.572 & 877 \\
\hline Abdominal circumference & 1.04 & 0.99 to 1.10 & 0.129 & 911 & 1.04 & 0.99 to 1.10 & 0.092 & 911 \\
\hline \multicolumn{9}{|l|}{ Conditional infant growth } \\
\hline \multicolumn{9}{|l|}{$0-6$ months } \\
\hline Length & 1.01 & 0.97 to 1.05 & 0.574 & 1450 & 0.98 & 0.94 to 1.03 & 0.409 & 1450 \\
\hline Weight & 1.08 & 1.03 to 1.12 & 0.000 & 1485 & 1.05 & 1.01 to 1.09 & 0.020 & 1485 \\
\hline Subscapular skinfold & 1.06 & 1.02 to 1.10 & 0.003 & 1480 & 1.05 & 1.01 to 1.10 & 0.017 & 1480 \\
\hline \multicolumn{9}{|l|}{$6-12$ months } \\
\hline Length & 0.97 & 0.93 to 1.02 & 0.307 & 1346 & 0.98 & 0.93 to 1.04 & 0.579 & 1346 \\
\hline Weight & 1.04 & 0.98 to 1.09 & 0.190 & 1372 & 1.06 & 1.00 to 1.12 & 0.041 & 1372 \\
\hline Subscapular skinfold & 1.06 & 1.01 to 1.10 & 0.010 & 1368 & 1.07 & 1.03 to 1.12 & 0.001 & 1368 \\
\hline
\end{tabular}

${ }^{*}$ Adjusted for gender, smoking during pregnancy, age last breastfed, maternal asthma, maternal rhinitis, paternal asthma, maternal education and birth order.

growth velocity between 11 and 19 weeks ( $R=0.90$ per SD increase, $\mathrm{p}=0.04$, table 5) and smaller 34 -week head circumference $(R R=0.91$ per $S D$ increase, $p=0.02$, see table 5 in online supplement). Similar to the associations for atopic wheeze, nonatopic wheeze risk increased by $6 \%$ per SD increase in adiposity gain from birth to 6 months $(p=0.02)$ and by $8 \%$ per SD increase in weight gain between 6 and 12 months ( $p=0.04$, table 5).
Similarly to atopic wheeze, postnatal length gain was not associated with the risk of non-atopic wheeze.

\section{Simultaneous analyses}

The conditional measures of growth velocity were calculated to ensure independence from initial size. Perhaps as a result, the relative risks for atopy, atopic wheeze and non-atopic wheeze

Table 4 Relative risks (RR) for the associations between prenatal and postnatal growth and whether the child had ever wheezed by age 3 years and was atopic compared with children who had never wheezed and were not atopic (unadjusted and adjusted) $(\mathrm{N}=542)$

\begin{tabular}{|c|c|c|c|c|c|c|c|c|}
\hline & \multicolumn{4}{|c|}{ Unadjusted analyses } & \multicolumn{4}{|c|}{ Adjusted* analyses } \\
\hline & $\overline{\mathbf{R R}}$ & $(95 \% \mathrm{Cl})$ & p Value & $\mathbf{n}$ & $\mathbf{R R}$ & (95\% CI) & p Value & $\mathbf{n}$ \\
\hline \multicolumn{9}{|l|}{ Birth size variables } \\
\hline Crown-heel length & 1.09 & 0.94 to 1.26 & 0.247 & 527 & 1.08 & 0.93 to 1.26 & 0.313 & 456 \\
\hline Weight & 1.06 & 0.91 to 1.23 & 0.461 & 537 & 1.02 & 0.87 to 1.19 & 0.810 & 465 \\
\hline \multicolumn{9}{|l|}{ Conditional fetal growth } \\
\hline \multicolumn{9}{|l|}{$\overline{11-19 \text { weeks }}$} \\
\hline Head circumference & 0.96 & 0.69 to 1.33 & 0.818 & 207 & 0.79 & 0.54 to 1.15 & 0.216 & 183 \\
\hline Abdominal circumference & 1.42 & 1.05 to 1.92 & 0.024 & 197 & 1.32 & 0.94 to 1.85 & 0.114 & 172 \\
\hline \multicolumn{9}{|l|}{ 19-34 weeks } \\
\hline Head circumference & 0.98 & 0.80 to 1.21 & 0.866 & 308 & 0.88 & 0.69 to 1.12 & 0.294 & 276 \\
\hline Abdominal circumference & 0.82 & 0.66 to 1.01 & 0.066 & 321 & 0.80 & 0.65 to 1.00 & 0.046 & 288 \\
\hline \multicolumn{9}{|l|}{ Conditional infant growth } \\
\hline \multicolumn{9}{|l|}{$0-6$ months } \\
\hline Length & 1.00 & 0.86 to 1.16 & 0.987 & 518 & 0.96 & 0.82 to 1.12 & 0.602 & 499 \\
\hline Weight & 1.25 & 1.09 to 1.43 & 0.001 & 530 & 1.22 & 1.03 to 1.43 & 0.020 & 460 \\
\hline Subscapular skinfold & 1.22 & 1.07 to 1.40 & 0.004 & 533 & 1.27 & 1.09 to 1.49 & 0.002 & 463 \\
\hline \multicolumn{9}{|l|}{$6-12$ months } \\
\hline Length & 1.02 & 0.85 to 1.22 & 0.829 & 497 & 0.98 & 0.80 to 1.20 & 0.842 & 432 \\
\hline Weight & 1.14 & 0.92 to 1.41 & 0.234 & 504 & 1.19 & 0.94 to 1.31 & 0.147 & 438 \\
\hline Subscapular skinfold & 1.14 & 0.99 to 1.32 & 0.073 & 502 & 1.20 & 1.03 to 1.39 & 0.018 & 436 \\
\hline
\end{tabular}

*Adjusted for gender, smoking during pregnancy, maternal asthma and maternal rhinitis, maternal atopy, paternal asthma, maternal education and birth order. 
Table 5 Relative risks (RR) for the associations between prenatal and postnatal growth and whether the child had ever wheezed by age 3 years but was not atopic compared with children who had never wheezed and were not atopic (unadjusted and adjusted) $(\mathrm{N}=970)$

\begin{tabular}{|c|c|c|c|c|c|c|c|c|}
\hline & \multicolumn{4}{|c|}{ Unadjusted analyses } & \multicolumn{4}{|c|}{ Adjusted* analyses } \\
\hline & $\overline{\mathbf{R R}}$ & (95\% Cl) & p Value & $\mathbf{n}$ & $\overline{\mathbf{R R}}$ & (95\% CI) & p Value & $\mathbf{n}$ \\
\hline \multicolumn{9}{|l|}{ Birth size variables } \\
\hline Crown-heel length & 0.97 & 0.92 to 1.03 & 0.282 & 944 & 0.97 & 0.92 to 1.03 & 0.317 & 926 \\
\hline Weight & 0.98 & 0.93 to 1.04 & 0.486 & 960 & 0.97 & 0.92 to 1.03 & 0.356 & 942 \\
\hline \multicolumn{9}{|l|}{ Conditional fetal growth } \\
\hline \multicolumn{9}{|l|}{ 11-19 weeks } \\
\hline Head circumference & 0.92 & 0.83 to 1.01 & 0.090 & 383 & 0.90 & 0.81 to 1.00 & 0.041 & 373 \\
\hline Abdominal circumference & 0.98 & 0.88 to 1.09 & 0.744 & 361 & 0.97 & 0.87 to 1.09 & 0.637 & 352 \\
\hline \multicolumn{9}{|l|}{ 19-34 weeks } \\
\hline Head circumference & 0.93 & 0.87 to 1.00 & 0.058 & 564 & 0.94 & 0.88 to 1.01 & 0.096 & 552 \\
\hline Abdominal circumference & 1.06 & 0.99 to 1.13 & 0.117 & 584 & 1.05 & 0.98 to 1.13 & 0.136 & 572 \\
\hline \multicolumn{9}{|l|}{ Conditional infant growth } \\
\hline \multicolumn{9}{|l|}{$0-6$ months } \\
\hline Length & 1.01 & 0.96 to 1.06 & 0.825 & 933 & 0.99 & 0.94 to 1.05 & 0.766 & 915 \\
\hline Weight & 1.05 & 1.00 to 1.10 & 0.044 & 952 & 1.04 & 0.99 to 1.10 & 0.093 & 934 \\
\hline Subscapular skinfold & 1.07 & 1.02 to 1.12 & 0.009 & 950 & 1.06 & 1.00 to 1.11 & 0.024 & 932 \\
\hline \multicolumn{9}{|l|}{$6-12$ months } \\
\hline Length & 0.97 & 0.91 to 1.03 & 0.320 & 878 & 0.98 & 0.92 to 1.05 & 0.636 & 862 \\
\hline Weight & 1.04 & 0.97 to 1.11 & 0.289 & 891 & 1.08 & 1.00 to 1.15 & 0.036 & 876 \\
\hline Subscapular skinfold & 1.00 & 0.95 to 1.06 & 0.929 & 887 & 1.02 & 0.96 to 1.09 & 0.465 & 871 \\
\hline
\end{tabular}

*Adjusted for gender, maternal age, smoking during pregnancy, maternal asthma, maternal rhinitis, paternal asthma, maternal education and birth order.

associated with measures of conditional prenatal abdominal growth and postnatal adiposity gain changed little after simultaneous inclusion of these growth measures in a multivariate analysis.

Formal testing showed no significant linear interactions between conditional 11-19 and 19-34-week abdominal growth velocities, or between 19-34-week abdominal growth and birth to 6 months adiposity gain in their predictions of outcomes. Subjects were grouped into thirds of growth velocity over the different time periods. The prevalences of childhood atopy and atopic wheeze were $27 \%$ and $38 \%$, respectively, in those in the top third of abdominal growth velocity from 11 to 19 weeks gestation and the bottom third of growth velocity in late pregnancy, indicating growth faltering in late pregnancy; comparable prevalences in those in the bottom third of abdominal growth velocity from 11 to 19 weeks gestation and the top third of growth velocity in late pregnancy were $4 \%$ and $6 \%$ for childhood atopy and atopic wheeze, respectively (figure 2). The association of postnatal adiposity gain with atopic wheeze was strongest in those with below average late pregnancy abdominal growth (see table 6 in online supplement); the prevalence was $35 \%$ in those in the bottom third of late pregnancy abdominal growth velocity and the top third of adiposity gain from birth to 6 months compared with $14 \%$ in those in the top third of late pregnancy abdominal growth velocity and the bottom third of early infancy adiposity gain. For non-atopic wheeze the prevalence was $68 \%$ in those in the bottom third of 19-34-week head circumference growth velocity and the top third of adiposity gain from birth to 6 months compared with $41 \%$ in those in the top third of 19-34-week head circumference growth velocity and the bottom third of early infancy adiposity gain (figure 3), with a similar pattern for adiposity gain from age 6-12 months (figure 3).

\section{Infant feeding}

As in other studies, formula-fed infants in the Southampton Women's Survey had greater weight and adiposity gains than breastfed infants. ${ }^{17}$ Stratified analyses showed, however, that the associations of infant weight and adiposity gains with early childhood wheeze, atopic and non-atopic wheeze were similar in breast and formula-fed infants.

\section{DISCUSSION}

Using conditional prenatal and postnatal growth velocities calculated from serial measurements of fetal and infant anthropometry, we examined the influences of prenatal and postnatal growth on wheeze and atopy at age 3 years. Rapid 11-19-week fetal abdominal growth followed by faltering of abdominal circumference growth was associated with later atopy, and late gestation abdominal growth faltering was associated with atopic wheeze. A lower early trajectory of prenatal head circumference growth was associated with non-atopic wheeze. Postnatal adiposity gain, but not linear growth, was associated with both atopic and non-atopic wheeze. The associations were independent of birth order, gestation, maternal atopy and smoking. These findings support our previous hypothesis that trajectories of growth before and after birth are associated with childhood respiratory health. ${ }^{4}$ Although wheezing and atopic disorders have overlapping and mixed phenotypes, our analyses suggest that factors which promote adaptive change in the relative growth of body tissues during fetal life and infancy can have later functional respiratory and immune consequences.

\section{Prenatal growth and wheeze and atopic outcomes}

In our analyses, faster abdominal growth velocity from 11 to 19 weeks gestation followed by growth faltering in late pregnancy was associated with later atopy. This suggests that the 
Figure 2 Prevalence of atopy and atopic wheeze at age 3 years according to groupings of $11-19$-week and 19-34-week abdominal circumference growth velocity, and according to 19-34-week abdominal circumference growth and adiposity gain from birth to 6 months.
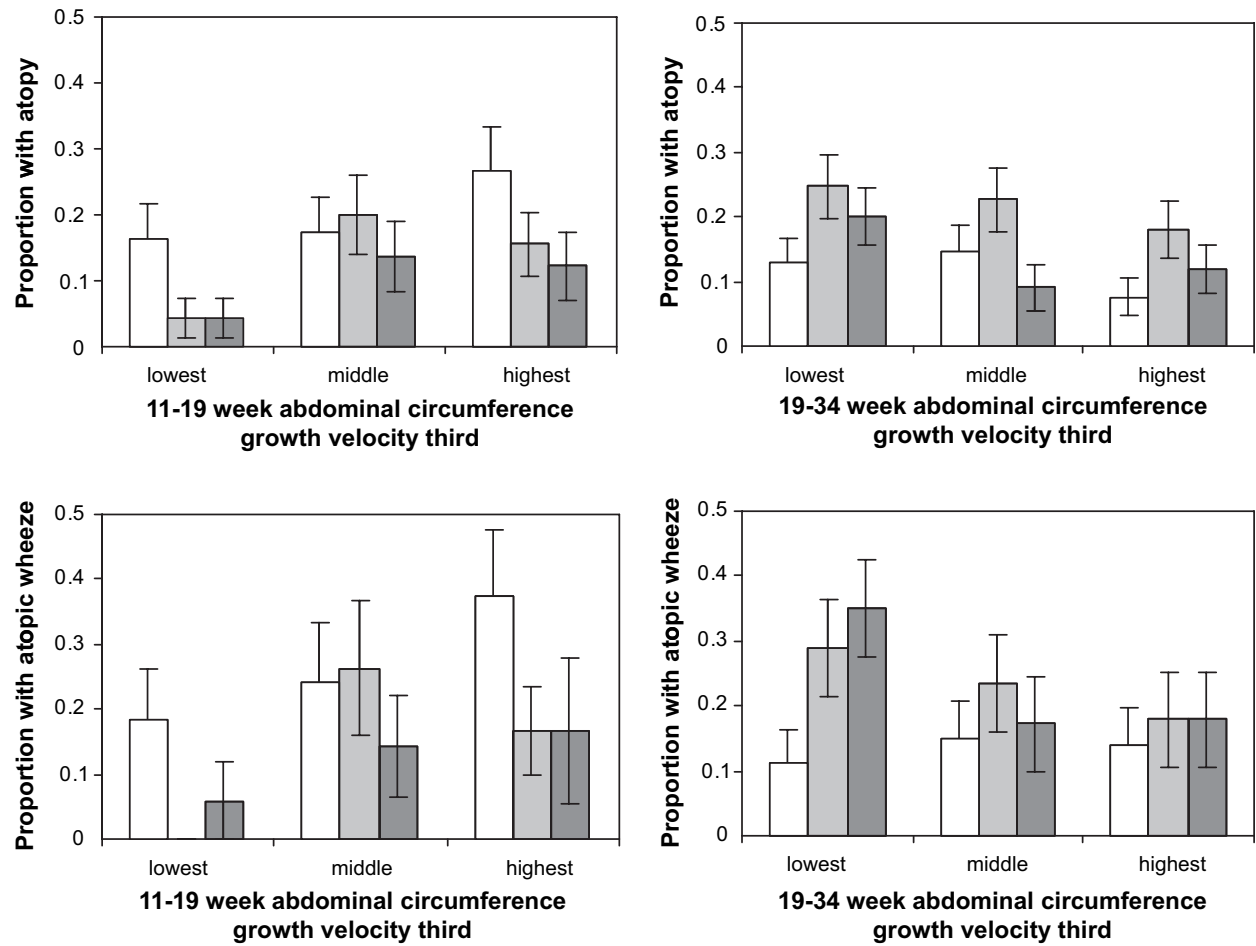

$\square$ Lowest abdominal circumference growth 19-34 weeks

Middle abdominal circumference growth 19-34 weeks

Highest abdominal circumference growth 19-34 weeks development of atopy is influenced by factors restricting growth in late gestation. Under conditions of intrauterine stress or restricted placental nutrient transfer in late gestation, brain growth is generally preserved at the expense of reduced accretion of abdominal soft tissue and fat. ${ }^{18}$ This results in asymmetrical growth restriction which is particularly marked in fetuses that initially follow a rapid growth trajectory. ${ }^{12}$ Atopy is believed to reflect a predominant Th2 lymphocyte response to common antigens. ${ }^{19}$ Animal studies show that poor fetal growth impairs thymic development ${ }^{20}$ and causes Th1/Th2 imbalance. ${ }^{21}$ Correlations between seasonal patterns of food availability and infant thymus size, ${ }^{22}$ cord blood lymphocyte count $^{23}$ and infectious deaths in young adulthood ${ }^{24}$ provide evidence for prenatal influences on human immune function.

Whereas atopic wheeze was also associated with faltering of abdominal circumference, non-atopic wheeze was associated with slower head circumference growth from both 11-19 and 19-34 weeks gestation; children who developed non-atopic wheeze were not, however, smaller at birth. This suggests that slowed growth in early gestation may be mechanistically linked to later susceptibility to wheeze. Early or extreme adversity might be associated with both slowed head growth and altered airway
Figure 3 Prevalence of non-atopic wheeze according to groupings of 19-34-week head circumference growth velocity and adiposity gain from birth to 6 months and 6-12 months.
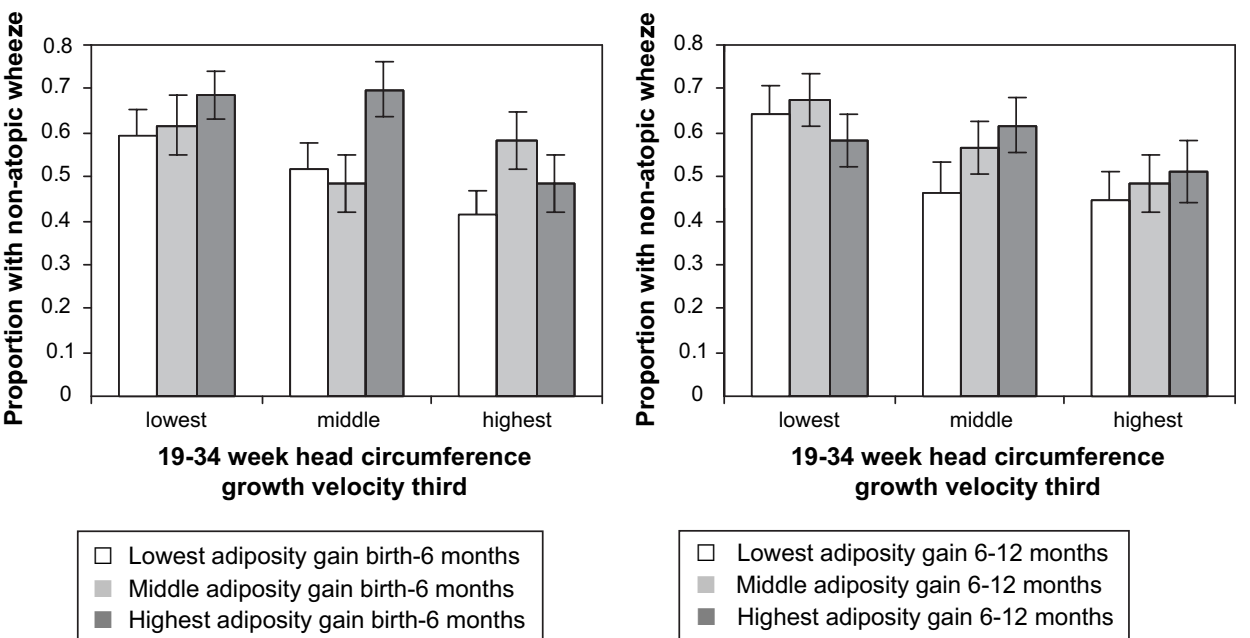

Error bars represent one standard error 
growth or altered respiratory mechanics that predispose to airway narrowing and wheeze during viral respiratory infections.

Experimental data support the central hypothesis that lung development and later function are sensitive to factors associated with fetal growth restriction, notably fetal hypoxaemia, reduced nutrient supply and hypercortisolaemia. For example, prenatal growth restriction in sheep is associated with reduced lung weight to body weight ratio, ${ }^{25}$ reduced alveoliarisation ${ }^{26}$ and reduced airway luminal area and airway wall cartilage. ${ }^{27}$ Growth restricted fetal lambs have altered lung structure ${ }^{26}$ and decreased respiratory and increased chest wall compliance ${ }^{28}$ which persist into postnatal life.

\section{Postnatal growth and wheeze and atopic outcomes}

The RR of atopy was not related to postnatal growth and adiposity gain. In contrast, independent of infant feeding, increased weight and adiposity gain during infancy were associated with an increased risk of wheezing before age 3 years. Similar associations were seen for non-atopic and atopic wheeze, although the effect size was greatest for atopic wheeze. The associations with weight and adiposity gain contrasted with the absence of associations with length gain.

Above average postnatal weight gain may be associated with the risk of atopic wheeze because late pregnancy growth faltering (associated with atopy in our study) tends to be followed by 'compensatory' increased postnatal weight gain unless prenatal nutrient restriction has been severe or prolonged. ${ }^{29}$ Alternatively, rather than serving as a marker of intrauterine growth restriction, above average postnatal weight gain may itself impair lung development. This is supported by the association between non-atopic wheeze and increased postnatal adiposity gain. Other studies have shown links between asthma and both high body mass index ${ }^{30}$ and rapid increases in weight ${ }^{31}$; while this may reflect common risk factors, increased adiposity in infancy may be mechanistically important in the development of asthma. Potential mechanisms include genetic polymorphisms, ${ }^{32}$ sex-specific hormonal changes, ${ }^{30}$ direct mechanical effects on lung function, ${ }^{33}$ altered immune response ${ }^{34}$ and increased susceptibility to gastric reflux. ${ }^{35}$

\section{Strengths and limitations}

The concept that birth anthropometry might predict future risk of wheezing and allergic disorders has been the subject of much investigation but little consensus. This is unsurprising as birth measurements only provide indirect evidence of the intrauterine environment. One strength of this study is the detailed assessment of prenatal growth afforded by serial ultrasound scans in a substantial sample of children broadly representative of the general population.

The principal limitations of this analysis arise from its observational nature and the likely non-homogeneity of the outcome groups; 'early childhood wheeze', for example, is likely to include children who wheeze only with viral respiratory infections and a smaller subgroup who may later develop persistent asthma. The strength of associations between risk factors and outcomes are likely to be lessened by such nonhomogeneity. Our study was not equally powered in relation to all outcomes or predictors; for example, there were $<150$ children in the 'atopic wheeze' group and only 542 children contributed data to analyses of this outcome. Fewer children had complete data for conditional measures of prenatal growth than for birth anthropometry owing to the need for two measurements to calculate the former. Power was also reduced by missing data for some confounding influences, notably maternal atopic status. The analyses conducted are independent so we have not formally adjusted for multiple testing; with the number of analyses undertaken, some findings may have arisen by chance and this should be considered when interpreting the findings.

In conclusion, we describe a pattern of rapid 11-19-week fetal abdominal growth velocity followed by growth faltering which is associated with later atopy and show that late gestation growth faltering is associated with atopic wheeze. This suggests that immune development is sensitive to programming by the prenatal environment. Moreover, we describe an association between postnatal adiposity gain and wheezing disorders; this may partly arise from impaired fetal growth which predisposes to 'compensatory' postnatal weight and adiposity gains, or may reflect mechanisms linked with adiposity per se. Slower prenatal growth was associated with non-atopic wheeze, and we speculate this may reflect smaller airway size.

Acknowledgements The authors acknowledge the help of the parents and infants who participated in this study. They are grateful to the staff of the Southampton Women's Survey for the collection of the birth and infant anthropometric measurements and to Dr Pam Mahon, Miss Jane Anderson and Mrs Corinne Nisbet for collection of the antenatal ultrasound data.

Funding Follow-up of children in the Southampton Women's Survey has been funded by the Medical Research Council, University of Southampton, British Heart Foundation and the Food Standards Agency (Contract No N05071). The research is supported by infrastructure provided by the NIHR Respiratory and Nutrition, Diet and Lifestyle Biomedical Research Units. KP was supported by a grant from the British Lung Foundation.

\section{Competing interests None.}

Ethics approval This study was conducted with the approval of the Southampton and South West Hampshire local research ethics committee.

Provenance and peer review Not commissioned; externally peer reviewed.

\section{REFERENCES}

1. Kotecha S, Watkins W, Heron J, et al. Spirometric lung function in school-age children: effect of intrauterine growth retardation and catch-up growth. Am J Respir Crit Care Med 2010;181:969-74.

2. Lawlor D, Ebrahim S, Davey Smith G. Association of birth weight and adult lung function: findings from the British Women's Heart and Health Study and a metaanalysis. Thorax 2005;62:396-402

3. Barker DJ, Godfrey KM, Fall C et al. Relation of birth weight and childhood respiratory infection to adult lung function and death from chronic obstructive airways disease. BMJ 1991;303:671-5.

4. Lucas JS, Inskip HM, Godfrey KM, et al. Small size at birth and greater postnatal weight gain: relationships to diminished infant lung function. Am J Respir Crit Care Med 2004:170:534-40.

5. Friedrich L, Stein RT, Pitrez PM, et al. Reduced lung function in healthy preterm infants in the first months of life. Am J Respir Crit Care Med 2006;173:442-7.

6. Martinez FD, Morgan WJ, Wright AL, et al. Initial airway function is a risk factor for recurrent wheezing respiratory illnesses during the first three years of life. Group Health Medical Associates. Am Rev Respir Dis 1991;143:312-16.

7. Dezateux C. Stocks J, Dundas I, et al. Impaired airway function and wheezing in infancy: the influence of maternal smoking and a genetic predisposition to asthma. Am J Respir Crit Care Med 1999;159:403-10.

8. Hancox R, Poulton R, Greene J, et al. Associations between birth weight, early childhood weight gain and adult lung function. Thorax 2009;64:226-32.

9. Ortquist A, Lundholm C, Carlstrom E, et al. Familial factors do not confound the association between birth weight and childhood asthma. Pediatrics 2009; 124:e737-47

10. Kindlund $\mathbf{K}$, Thomsen S, Stensballe L. Birth weight and risk of asthma in 3-9 year old twins: exploring the fetal origins hypothesis. Thorax 2010;65:146-9.

11. Turner S, Zhang G, Young S, et al. Associations between postnatal weight gain, change in postnatal pulmonary function, formula feeding and early asthma. Thorax 2008;63:234-9.

12. Campbell S, Thoms A. Ultrasound measurement of the fetal head to abdomen circumference ratio in the assessment of growth retardation. Br J Obstet Gynaecol 1977;84:165-74

13. Baker PN, Johnson IR, Gowland PA, et al. Measurement of fetal liver, brain and placental volumes with echo-planar magnetic resonance imaging. $\mathrm{Br} \mathrm{J} \mathrm{Obstet}$ Gynaecol 1995;102:35-9. 
14. Inskip HM, Godfrey KM, Robinson S, et al. Cohort profile: The Southampton Women's Survey. Int J Epidemiol 2006;35:42-8.

15. Royston P. Calculation of unconditional and conditional reference intervals for foetal size and growth from longitudinal measurements. Stat Med 1995:14:1417-36.

16. Barros A, Hirakata V. Alternatives for logistic regression in cross-sectional studies: an empirical comparison of models that directly estimate the prevalence ratio. BMC Med Res Methodol 2003;3:21.

17. Baird J, Poole J, Robinson S, et al. Milk feeding and dietary patterns predict weight and fat gains in infancy. Paediatr Perinat Epidemiol 2008:22:575-86.

18. Rudolph AM. The fetal circulation and its response to stress. J Dev Physiol 1984;6:11-19.

19. Prescott SL, Macaubas C, Smallacombe T, et al. Development of allergen-specific T-cell memory in atopic and normal children. Lancet 1999;353:196-200.

20. Lang U, Baker RS, Khoury J, et al. Effects of chronic reduction in uterine blood flow on fetal and placental growth in the sheep. Am J Physiol Regul Integr Comp Physiol 2000;279:R53-9.

21. Bass H, Adkins B, Strober S. Thymic irradiation inhibits the rapid recovery of TH1 but not TH2-like functions of CD4+ T cells after total lymphoid irradiation. Cell Immunol 1991;137:316-28.

22. Collinson AC, Moore SE, Cole TJ, et al. Birth season and environmental influences on patterns of thymic growth in rural Gambian infants. Acta Paediatr 2003;92:1014-20.

23. Collinson AC, Ngom PT, Moore SE, et al. Birth season and environmental influences on blood leucocyte and lymphocyte subpopulations in rural Gambian infants. BMC Immunol 2008;9:18

24. Moore SE, Cole TJ, Poskitt EM, et al. Season of birth predicts mortality in rural Gambia. Nature 1997;388:434
25. Maloney JE, Bowes G, Brodecky V et al. Function of the future respiratory system in the growth retarded fetal sheep. J Dev Physiol 1982;4:279-97.

26. Maritz GS, Cock ML, Louey $S$, et al. Effects of fetal growth restriction on lung development before and after birth: a morphometric analysis. Pediatr Pulmonol 2001;32:201-10

27. Wignarajah D, Cock ML, Pinkerton KE, et al. Influence of intrauterine growth restriction on airway development in fetal and postnatal sheep. Pediatr Res 2002;51:681-8.

28. Joyce BJ, Louey S, Davey MG, et al. Compromised respiratory function in postnata lambs after placental insufficiency and intrauterine growth restriction. Pediatr Res 2001:50:641-9.

29. Tanner JM. Catch-up growth in man. Br Med Bull 1981;37:233-8.

30. Camera PL, Zeiger R, Guilbert T, et al. Relationship between infant weight gain and later asthma. Pediatr Allergy Immunol 2009;21:82-9.

31. Castro-Rodriguez JA, Holberg CJ, Morgan WJ, et al. Increased incidence of asthma like symptoms in girls who become overweight or obese during the schoo years. Am J Respir Crit Care Med 2001;163:1344-9.

32. Hallstrand TS, Fischer ME, Wurfel MM, et al. Genetic pleiotropy between asthma and obesity in a community-based sample of twins. J Allergy Clin Immunol 2005:116:1235-41.

33. Zerah F, Harf A, Perlemuter $L$, et al. Effects of obesity on respiratory resistance. Chest 1993;103:1470-6.

34. Weisberg SP, McCann D, Desai M, et al. Obesity is associated with macrophage accumulation in adipose tissue. J Clin Invest 2003;112:1796-808.

35. Gunnbjornsdottir MI, Omenaas E, Gislason T, et al. Obesity and nocturnal gastrooesophageal reflux are related to onset of asthma and respiratory symptoms. Eur Respir J 2004;24:116-21.

\section{Lung alert}

\section{Step-up treatment for children with uncontrolled asthma}

Uncontrolled asthma can occur in children receiving low dose inhaled corticosteroids, but evidence to guide step-up treatment is currently lacking. In this study, 182 children (6-17 years of age) with uncontrolled asthma on $100 \mu \mathrm{g}$ of fluticasone twice daily were randomly assigned to receive each of three blinded step-up treatments in a random order for a total of 48 weeks. During each 16 week period patients received: $100 \mu \mathrm{g}$ of fluticasone plus $50 \mu \mathrm{g}$ of the long-acting $\beta$-agonist salmeterol twice daily (LABA step-up), $250 \mu \mathrm{g}$ of fluticasone twice daily (ICS step-up) or $100 \mu \mathrm{g}$ of fluticasone twice daily plus 5 or $10 \mathrm{mg}$ of the leukotriene receptor anatagonist montelukast once daily (LTRA step-up).

A differential response to each of the three treatments was determined using three asthma control measures: use of oral prednisolone in acute exacerbations, number of asthma control days and forced expiratory volume in $1 \mathrm{~s}\left(\mathrm{FEV}_{1}\right)$. The ability of prespecified baseline covariates to predict patterns of treatment response was assessed. Of the 165 patients evaluated, 161 (98\%) showed a differential response, with the best response during LABA step-up treatment occurring significantly more frequently than during LTRA or ICS step-up. Higher scores in the asthma control test (better control at baseline) and white race predicted better responses to LABA step-up.

Although this study showed better responses to LABA step-up, many children had the best responses with both of the other step-up treatments. This highlights the need for regular monitoring in child asthma therapy when stepping up treatment.

Lemanske RF, Mauger DT, Sorkness CA, et al. Stepup therapy for children with uncontrolled asthma receiving inhaled corticosteroids. N Engl J Med 2010;362:975-85.

\section{Claire Chambers}

Correspondence to Claire Chambers, University College London, UK; claire.chambers@ucl.ac.uk

Published Online First 29 October 2010

Thorax 2010;65:1106. doi:10.1136/thx.2010.145573 